Nursing Arts

Vol XIII, No 02, Desember 2019,

ISSN: 1978-6298 (Print), 2686-133X (Online)

\title{
EFEKTIFITAS PENGGUNAAN VIDEO SEBAGAI MEDIA EDUKASI BAGI PENINGKATAN PENGETAHUAN DAN PERUBAHAN PERILAKU IBU HAMIL DALAM PENANGANAN MALARIA ${ }^{1}$ Yuni Subhi Isnaini, ${ }^{2}$ Bahrah ${ }^{1,2}$ Politeknik Kesehatan Kemenkes Sorong, Sorong, Indonesia email: yunisubhi@gmail.com
}

\author{
Article History \\ Dikirim, Desember $08^{\text {th }}, 2019$ \\ Ditinjau, Desember $13^{\text {th }}, 2019$ \\ Diterima,Desember $19^{\text {th }}, 2019$
}

\begin{abstract}
According to the World Health Oganitation (WHO), around $40 \%$ of the world's population lives with malaria endemic areas. WHO estimates that in 2015 there will be around 214 million new cases of malaria with the death of around 438 thousand people worldwide. The purpose of this study was to analyze the effectiveness of the use of video as an educational medium in increasing knowledge and behavior changes in pregnant women in handling malaria in Wamesa District, South Manokwari in 2019. This study used a Quasy Experiment research method with one group only pre post test design. The population in this study was pregnant women with a total sample of 18 pregnant women. Data analysis used univariate analysis in the form of frequency distribution, bivariate analysis used Wilcoxon statistical test at 95\% confidence level. Statistical test results on the knowledge variable obtained p-value $=0.434$ where there is no effect of differences in the level of knowledge of respondents before and after video education media provided about malaria management, while the variable behavior change obtained pvalue $=0.004$ where there is the influence of differences in behavior change respondents before and after being given a video education media about malaria management. The conclusion in the study there was no effect of differences in the level of knowledge of respondents before and after the video education media was given about malaria management and there was an effect of differences in the behavior of respondents before and after being given a video education media about malaria management
\end{abstract}

Keywords: Knowledge, Behavior Change, Use of Video Education Media ABSTRAK

Menurut World Health Oganitation (WHO), sekitar 40\% dari penduduk dunia yang tinggal dengan wilayah endemik malaria. WHO memperkirakan pada Tahun 2015 terjadi sekitar 214 juta kasus baru malaria dengan kematian sekitar 438 ribu orang di penjuru dunia. Tujuan penelitian ini adalah untuk menganalisis efektifitas penggunaan video sebagai media edukasi dalam peningkatan pengetahuan dan perubahan perilaku Ibu Hamil dalam penanganan malaria di Wamesa Distrik Manokwari Selatan tahun 2019. Penelitian ini menggunakan metode dengan jenis penelitian Quasy Eksperimen dengan desain one group only pre post test desain. Populasi dalam penelitian ini adalah ibu hamil dengan jumlah sampel sebanyak $18 \mathrm{ibu}$ hamil. Analisis data menggunakan analisis univariat berupa distribusi frekuensi, analisis bivariat mengguakan uji statistik Wilcoxon pada tingkat kepercayaan 95\%. Hasil uji statistik pada variabel pengetahuan didapatkan nilai -value $=0,434$ (tidak ada pengaruh perbedaan tingkat pengetahuan responden sebelum dan sesudah diberikan media edukasi video tentang penanganan malaria), sedangkan pada variabel perubahan perilaku didapatkan nilai p-value = 0,004, ada pengaruh perbedaan perubahan perilaku responden sebelum dan sesudah diberikan media edukasi video tentang penanganan malaria. Kesimpulan : tidak ada pengaruh perbedaan tingkat pengetahuan responden sebelum dan sesudah diberikan media edukasi video tentang penanganan malaria dan ada pengaruh perbedaan perubahan perilaku responden sebelum dan sesudah diberikan media edukasi video tentang penangaan malaria.

Kata Kunci : Pengetahuan, Perubahan Perilaku, Penggunaan Media Edukasi Video. 


\section{PENDAHULUAN}

Malaria ialah penyakit infeksi yang disebabkan dengan parasit genusplsmodium serta disebarkan oleh nyamuk anopheles, namun diawali seperti gejala demam, menggigil, serta anemia (Kemenkes RI) namun gejala ini memang tidak khas dengan sakit malaria, namun bisa terjadi dengan penyakit lain. dikarenakan kita tinggal di Tanah Papua (Goverment, 2017). Malaria merupakan suatu penyakit infeksi dengan demam berkala yangdisebabkan oleh parasit plasmodium (termasuk protozoa) dan ditularkan oleh nyamuk anopheles betina (Akhsin, 2010 dalam Harahap, 2012) (Natalia, 2012).

Menurut World Health Oganitation (WHO), sekitar 40\% dari penduduk dunia yang tinggal dengan wilayah endemik malaria. WHO memperkirakan pada Tahun 2015 terjadi sekitar 214 juta kasus baru malaria dengan kematian sekitar 438 ribu orang di penjuru dunia (Darmiah, 2017).

Di perkirakan tahun 2015 malaria menyerang 106 negara didunia. Malaria ialah salah satu indikator merupakan target Pembangunan Milinium (MDGs), ialah dengan menghentikan penyebaran serta mengurangi insiden malaria pada tahun 2015. Komitmen global dengan Melineum Development Goals (MDGs) menempatkan upaya pemberantasan malaria dengan satu tujuan MDGs serta harus mencapai pada tahun 2015 ialah menanggulangi HIV/AIDS, malaria, serta Tuberkulosis, berakhirnya MDGs tahun 2015 komitmen Global dilanjutkan sebagai Sustainable Develoment Goals (SDGs) terdapat dalam tujuan ke 3 ialah menjamin kehidupan sehat serta mengupayakan kesejahteraan ke orang serta tujuan spesifik dan mengakhiri epidemi AIDS, Tuberkulosis, Malaria penyakit neglected -tropikal sampai pada tahun 2030 (Ocurencce, 2018).

Secara alamiah, penularan malaria terjadi karena adainteraksi antara agent (parasit Plasmodium spp), host definitive (nyamuk Anopheles spp) serta host intermediate (manusia) dan penularan malaria mempengaruhi keberadaan fluktuasi populasi vektor (penular yaitu nyamuk Anopheles spp), yang salah satunya dipengaruhi oleh intensitas curah hujan, serta sumber parasit Plasmodium spp (Hakim, 2011).

Upaya penanggulangan penyakit malaria sudah dilakukan di Indonesia sejak 2007 serta di pantau dengan menggunakan Annual parasite incidance (API), kebijakan mensyaratkan berbagai kasus malaria harus membuktikan hasil pemeriksaan persediaan darah sebagai kasus positif tetapdi obati, pengobatan berbasis kombinasi artemicine atau AC (Artemicine -based combination Therapies).

API nasional telah mengalami penurunan dari tahun 2008-2009 dari 2,47 per 1000 penduduk menjadi 1,85 per 1000 penduduk. Hal ini masih dilakukan dengan mencapai target Renstra Kemenkes tahun 2010sampai 2011 adalah API harus menurunkan menjadi 1 per 1000 penduduk pada tahun 2014 (Darmiah, 2017). Masalah kesehatan berbasis lingkungan menyebabkan kondisi yang tidak memadai, mengakibatkan penyakit diantaranya diare, ISPA, TB Paru, malaria, dan lainnya masih ada. Malaria ialah penyakit menular serta masih menjadi masalah serius di dunia. Risiko kematian mengakibatkan penyakit 
malaria lebih tinggi dibandingkan penyakit infeksi lainnya. Per tahun diperkirakan menjadi 300 sampai 500 juta kasus malaria dan beberapa juta mortalitas sebagian besar mengakibatkan pada anak-anak. Malaria pada umumnya terjadi dibelahan dunia antara 450LU dan 40'LS.

Sekitar $35 \%$ penduduk Indonesia tinggal di daerah berisiko terinfeksi malaria. Sebanyak 38 ribu orang dilaporkan meninggal per tahun karena malaria berat akibat Plasmodium falciparum. Tahun 2010 terdapat 465.764 kasus positif malaria walaupun angka ini telah menurun pada tahun 2015 menjadi 209.413 kasus. Beberapa wilayah telah dikategorikan sebagai daerah zona merah penderita malaria seperti Nusa Tenggara Timur, Nusa Tenggara Barat, Maluku, Maluku Utara, Kalimantan Tengah, Bangka Belitung, Kepulauan Riau, dan Bengkulu. Berikutnya, Jambi, Sulawesi Tengah, Sulawesi Barat, Gorontalo, serta Aceh.5 Tujuan umum program malaria adalah membebaskan Indonesia dari penyakit malaria. Pembebasan Kalimantan dan Sulawesi (2020), serta Papua Barat, Maluku, NTT, dan Maluku Utara (2030).

Angka kesakitan malaria di Provinsi Papua dalam kurun waktu 2005-2010 berkisar sebesar 193-224 per 1000 penduduk. Ini merupakan tertinggi di Indonesia. Malaria dianggap sebagai penyebab kematian utama bagi semua kelompok umur di Papua walaupun data kongkretnya belum dapat diperoleh. Di daerah endemis malaria, penyakit ini menyumbang angka kesakitan anemia dan kematian ibu hamil. Malaria menyebabkan ibu hamil melahirkan bayi dengan berat bayi lahir rendah, prematur dan juga kematian bayi. Akibat lainnya klien dalam usia produktifakan menurun produktifitasnya (Suci, 2013).

Salah satu penyebab masih tingginya kejadian malaria yaitu akibat adanya faktor perilaku dan pengetahuan. Tingkah laku manusia adalah corak kegiatan yang sangat dipengaruhi oleh faktor yang ada dalam dirinya. Faktor-faktor intern yang dimaksud antara lain jenis ras/keturunan, jenis kelamin, sifat fisik, kepribadian, bakat, dan intelegensia ( $\mathrm{Li}, 2009)$.

Pengetahuan merupakan sublimasi atau intisari dan berfungsi sebagai pengendali moral dari pada pluralitas keberadaan ilmu pengetahuan (Bandura et al., 2008). Peningkatan pengetahuan dapat diperoleh melalui pemberian informasi. Informasi mempengaruhi pengetahuan seseorang jika seringmendapatkan informasi tentang suatu pembelajaran maka akan menambah pengetahuan dan wawasannya, sedangkan seseorang yang tidak sering menerima informasi tidak akan menambah pengetahuan dan wawasannya (Budiman dan Riyanto, 2016).

Studi awal yang penulis lakukan di Puskesmas Maripi, didapatkan kejadian malaria pada tahun 2018 sebanyak 373 penderita dan kejadian malaria yang terdiri dari ibu hamil sebanyak 15 dan pada balita sebanyak 151 serta penduduk dewasa 207 orang, upaya yang telah dilakukan di puskesmas maripi adalah memberikan kelambu pada keluarga dan semua ibu hamil diwilayah Puskesmas Maripi dan pengobatan pada penderita. 


\section{METODE}

Penelitian ini merupakan jenis penelitian Quasy Eksperimental dengan rancangan penelitian Pre Post Test Only One Group Desain (Zakiyatun, 2017). Penelitian ini dilakukan di Puskesmas Maripi Kabupaten Manokwari di Indonesia. Penelitian ini menggunakan 1 kelompok penelitian yang akan diberikan intervensi pemberian vidoe sebagai media media edukasi dalam penanganan malaria selama 14 hari untuk mengetahui tingkat pengetahuan dan perubahan perilaku sebelum dan setelah diberikan video. Pengukuran tingkat pengetahuan dilakukan sebelum diberikan video dan setelah diberikan video pada hari ke 14 , sedangakn perubahan perilaku diukur sebelum diberikan video dan diukur setelah diberikan video pada hari ke 7 dan hari ke 14 .

Populasi adalah ibu hamil yang ada di Puskesmas maripi dengan besar sampel sebanyak 18 responden yang memenuhi kriteria inklusi berdasarkan teknik sampling purposive sampling. Untuk menjawab hipotesis membuktikan ada pengaruh perbedaan tingkat pengetahuan dan perubahan perilaku responden sebelum dan sesudah diberikan media edukasi video tentang penanganan malaria dianalisis menggunakan uji Wilcoxon.

\section{HASIL}

\section{Karakteristik responden}

Berdasarkan tabel 1, karakteristik responden diinterpretasikan usia terbanyak yaitu pada usia 20-35 tahun berjumlah 15 (83\%), sedangkam karakteristik reponden dari segi pendidikan, pendidikan yang paling banyak yaitu responden dengan pendidikan menengah dan tinggi berjumlah $7(38,9)$ serta karakteristik responden dari segi pekerjaan yang paling banyak adalah responden dengan tidak bekerja atau sebagai ibu rumah tangga berjumlah 15 (83\%). 
Tabel 1 Jumlah dan persentase karakteristik responden

\begin{tabular}{|c|c|c|c|}
\hline No. & Variabel & $\mathbf{n}$ & $\%$ \\
\hline \multirow[t]{3}{*}{1} & Usia & & \\
\hline & 20-35 Tahun & 15 & 83 \\
\hline & 36-45 Tahun & 3 & 16,6 \\
\hline \multirow[t]{4}{*}{2} & Pendidikan & & \\
\hline & Dasar & 4 & 22,2 \\
\hline & Menengah & 7 & 38,9 \\
\hline & Tinggi & 7 & 38,9 \\
\hline \multirow[t]{3}{*}{3} & Pekerjaan & & \\
\hline & Bekerja & 3 & 16,6 \\
\hline & Tidak bekerja & 15 & 83 \\
\hline
\end{tabular}

\section{Analisis Univariat}

Berdasarkan tablel 2, hasil uji normalitas menunjukkan bahwa tingkat pengetahuan responden menunjukkan hasil pada tingkat pengetahuan sebelum diberikan intervensi berdistribusi tidak normal dengan nilai $\mathrm{p}$ value $<0,05$, sedangkan pada tingkat pengetahuan setelah intervensi berdistribusi normal dengan nilai $\mathrm{p}$ value $>0,05$. Hasil uji normalitas pada variabel perilaku responden menunjukkan hasil pada perilaku sebelum dan setelah diberikan intervensi berdistribusi tidak normal yaitu dengan nilai $\mathrm{p}$ value < 0,05 .

Tabel 2 Hasil uji normalitas variabel pengetahuan dan perilaku pre dan post test

\begin{tabular}{cccc}
\hline No. & Variabel & n & P value \\
\hline \multirow{2}{*}{1} & Pengetahuan Pre & 18 & 0,000 \\
& Pengetahuan post & 18 & 0,502 \\
& & & \\
& Perilaku pre & 18 & 0,011 \\
2 & Perilaku post & 18 & 0,000
\end{tabular}

Keterangan : hasil uji normalitas Shapiro-Wilk, significant $>0.05$

\section{Analisis Bivariat}

Sajian analisa data bivariat dalam penelitian ini untuk membuktikan pengaruh efektifitas penggunaan Video sebagai media edukasi bagi peningkatan pengetahuan dan perubahan perilaku Ibu Hamil dalam penanganan malaria di wamesa distrik manokwari selatan tahun 2019. 
1. Analisa data bivariat pengaruh efektifitas pengunaan Video sebagai media edukasi terhadap peningkatan pengetahuan

Berdasarkan tabel 3, hasil penelitian dapat diinterpretasikan bahwa sebelum diberikan media video edukasi pengetahuan responden nilai rata-rata atau mean 64,86 dengan standar deviasi
11,12 dan meningkat menjadi 67,19 dengan standar deviasi 8,76 sesudah diberikan media video edukasi. Hasil uji statistik Wilcoxon pada pengetahuan didapatkan p-value $(0,434)$ atau nilai $\mathrm{p}>0,05$ yang artinya tidak ada perbedaan antara pengetahuan responden sebelum dan sesudah diberikan media video edukasi tentang penanganan malaria.

Tabel 3 Pengaruh efektifitas pengunaan Video sebagai media edukasi terhadap peningkatan pengetahuan

\begin{tabular}{ccccc}
\hline No & Pengetahuan & Min_Max & Mean \pm SD & P value \\
\cline { 1 - 3 } 1 & Pre_test & $26,30 \pm 78,90$ & $64,86 \pm 11,12$ & \\
\cline { 1 - 3 } 2 & Post_test & $52,60 \pm 84,20$ & $67,19 \pm 8,76$ & 0,434
\end{tabular}

Significant $P$ value $<0.05$ Wilcoxon Test

2. Analisa data bivariat pengaruh efektifitas pengunaan Video sebagai media edukasi terhadap perubahan perilaku

Berdasarkan tabel 3, hasil penelitian dapat diinterpretasikan bahwa sebelum diberikan media video edukasi perilaku responden nilai rata-rata atau mean 2,7 dengan standar deviasi 1,06 dan meningkat menjadi 3,6 dengan standar deviasi 0,84 sesudah diberikan media video edukasi. Hasil uji statistik Wilcoxon pada perilaku didapatkan pvalue $(0,004)$ atau nilai $p<0,05$ yang artinya ada perbedaan antara perilaku responden sebelum dan sesudah diberikan media video edukasi tentang penanganan

Tabel 4 Pengaruh efektifitas pengunaan Video sebagai media edukasi terhadap perubahan perilaku

\begin{tabular}{ccccc}
\hline No & Perilaku & Min_Max & Mean \pm SD & P value \\
\hline 1 & Pre_test & $1 \pm 4$ & $2,7 \pm 1,06$ & \\
\cline { 1 - 3 } 2 & Post_test & $1 \pm 4$ & $3,6 \pm 0,84$ & 0,004 \\
& & & & \\
\hline
\end{tabular}

Significant P value $<0.05$ Wilcoxon Test 


\section{PEMBAHASAN}

\section{Pengaruh efektifitas pengunaan Video sebagai media edukasi terhadap peningkatan pengetahuan tentang penanganan malaria}

Hasil penelitian menunjukan bahwa nilai rerata skor pengetahuan responden meningkat sesudah diberikan media edukasi menggunakan video, walaupun tidak begitu terjadi peningkatan nilai rerata yang signifikan. Variabel pengetahuan diukur 1 kali sebelum diberikan video dan 14 hari sesudah diberikan video. Dilakukan dengan mengisi kuesioner yang diberikan kepada responden pada minggu kedua setelah selesai diberikan video. Dalam proses edukasi yang dilakukan dengan responden menggunakan video sebagai media edukasi. Video diberikan kepada tiap responden sebagai bahan bacaan dan media pada saat melakukan edukasi. Video yang diberikan kepada responden berisi tentang cara penanganan malaria. Hasil dari kuesioner yang diberikan tentang pengetahuan yaitu ditemukan beberapa responden banyak menjawab salah pada pertanyaaan tentang pengetahuan dasar mengenai malaria.

Hasil uji statistik wilcoxon pada pretest dan postest pengetahuan didapatkan p-value $=0,434$ ini berarti tidak ada pengaruh edukasi dengan media video terhadap pengetahuan sebelum dan sesudah diberikan edukasi di Puskesmas Maripi Tahun 2019. Berbagai faktor yang dapat mempengaruhi terjadinya malaria diantaranya adalah pengetahuan terhadap penanganan malaria. Pengetahuan merupakan faktor yang sangat penting yang dapat membentuk tindakan atau perilaku seseorang, karena merupakan hasil tahu dari seseorang atas penginderaan dari suatu objek tertentu (Meidina, 2017).

Promosi kesehatan merupakan salah satu upaya yang dapat dilakukan untuk meningkatkan pengetahuan salah satunya melalui penyuluhan. Namun berhasilnya penyuluhan kesehatan tersebut pada masyarakat tergantung pada komponenn pembelajaran. Media penyuluhan kesehatan merupakan salah satu komponen dari proses pembelajaran. Media yang menarik akan memberikan keyakinan, sehingga perubahan kognitif afeksi dan psikomotor dapat dipercepat. Audiovisual merupakan salah satu media yang menyajikan informasi atau pesan secara audio dan visual (Hidayatullah, 2017).

Media penyuluhan dengan audio visual memberikan stimulus terhadap mata (penglihatan) dan telinga (pendengaran), sedangkan media cetak hanya menstimulasi indra mata (penglihatan). Mengingat pentingnya promosi kesehatan maka perlu adanya metode pembelajaran atau inovasi baru agar audiens bisa menerima pesan kesehatan dengan baik. Dalam penyuluhan kesehatan, banyak media yang digunakan untuk menunjang efektivitas penyuluhan kesehatan, media cetak seperti booklet, leaflet dan lain-lain merupakan media yang sering di gunakan, sedangkan media audio visual adalah media yang jarang digunakan dalam penyuluhan kesehatan maupun pembelajaran. Pemberian pengetahuan lebih menarik jika disampaikan dengan metode dan media yang menarik pula (Hidayatullah, 2017). 
Penyuluhan dalam penelitian ini mengunakan media audio visual berupa video kesehatan tentang penanganan malaria. Materi dalam video lebih banyak menampilkan bentuk-bentuk penanganan malaria yang dibuat atau dikemas secara menarik sehingga responden tertarik untuk membacanya dan tidak bosan. Seperti yang diketahui bahwa masyarakat terkadang cenderung bosan apabila penyuluhan kurang menarik apalagi apabila penyuluhan dalam video tersebut membutuhkan waktu yang cukup lama untuk dibaca sehingga sudah tepat apabila video yang dibawakan dibuat dan dicari yang semenarik mungkin agar menarik perhatian responden. Video yang digunakan pada saat penyuluhan kesehatan dibuat dan dicari yang semenarik mungkin dengan mempertimbangkan minat responden yang cenderung lebih menyukai hal-hal baru dan unik serta adanya gambar yang menarik untuk menarik perhatian responden. Media video dalam penyuluhan ini dibuat oleh peneliti sendiri dengan menggunakan buku panduan kebas malaria (keluarga bebas malaria). Dalam menentukan media dan alat bantu penyuluhan kesehatan, peneliti mengacu pada pernyataan bahwa pengetahuan yang ada pada setiap manusia itu diterima atau ditangkap melalui panca indra. Semakin banyak indra yang digunakan untuk menerima sesuatu maka semakin banyak dan semakin jelas pengertian/ pengetahuan yang diperoleh (Hidayatullah, 2017).

Namun hasil penelitian ini tidak sejalan dengan beberapa hasil penelitian tentang penggunaan media audio visual salah satunya penelitian yang dilakukan oleh Meidiana Tahun 2018, dimana hasil penelitian menunjukkan bahwa penggunaan audio visual dapat meningkatkan pengetahuan dan sikap remaja yang overweight (Meidina, 2017).

Pada penelitian ini diperoleh hasil penelitian menunjukkan bahwa tidak ada perbedaan skor pengetahuan responden sebelum dan setelah diberikan media video tentang penanganan malaria, hal disebebkan karena beberapa faktor yang dapat menjadi alasan yaitu dimana kurangnya waktu penelitian yang lebih lama sehingga responden akan lebih lama untuk membaca video yang diberikan dan perlunya pengawasan terhadap responden apakah responden benar-benar memiliki waktu untuk menonton atau membaca video yang diberikan. Selain itu masyarakat di Provinsi Papua Barat telah membentuk opini atau pendapat dalam akal pikirannya tentang penyakit malaria yang bukan lagi hal yang baru dan sering didengar, sehingga masyarakat merasa sudah memahami tentang malaria. Namun pemahaman tersebut masih hanya dimiliki oleh masyarakat mengenai pengetahuanpengetahuan dasar dan masyarakat lebih tertarik dengan langsung melakukan action atau praktik terhadap penanganan malaria.

Berdasarkan alasan diatas perlunya waktu penelitian yang lebih lama sehingga responden akan lebih lama untuk membaca video yang diberikan karena media audio-visual tidak saja menghasilkan cara belajar yang efektif dalam waktu yang lebih singkat, akan tetapi apa yang diterima melalui media audio-visual lebih lama dan lebih baik tinggal dalam ingatan (Doro, 2016). 


\section{Pengaruh efektifitas pengunaan Video sebagai media edukasi terhadap perubahan perilaku tentang penanganan malaria}

Hasil penelitian menunjukan bahwa nilai rerata skor perilaku responden meningkat sesudah diberikan media edukasi menggunakan video, walaupun tidak begitu terjadi peningkatan nilai rerata yang signifikan. Variabel perilaku diukur 1 kali sebelum diberikan video dan hari ke 7 dan hari ke 14 sesudah diberikan video. Dilakukan dengan melakukan observasi terhadap perilaku responden pada minggu pertama dan kedua setelah selesai diberikan video. Dalam proses edukasi yang dilakukan dengan responden menggunakan video sebagai media edukasi tujuannya agar adanya perubahan perilaku dalam penanganan malaria. Video yang diberikan kepada responden berisi tentang cara penanganan malaria salah satunya yaitu perilaku dalam pencegahan malaria. Hasil dari observasi yaitu ditemukan beberapa responden banyak mengalami perubahan perilaku yaitu mengalami perubahan perilaku yang tadinya hanya melakukan 2 tindakan pencegahan yaitu menghindari gigitan nyamuk dan membunuh nyamuk namun terjadi peningkatan perubahan dengan melakukan semua atau 4 pencegahan yaitu dengan juga melakukan membasmi telur dan jentik nyamuk serta menghilangkan sarang nyamuk.

Hasil uji statistik wilcoxon pada pretest dan postest pengetahuan didapatkan p-value $=0,004$ ini berarti ada pengaruh edukasi dengan media video terhadap perilaku sebelum dan sesudah diberikan edukasi di Puskesmas Maripi Tahun 2019. Pengetahuan (knowledge), sikap (attitude) dan tindakan (practice) merupakan tahapan perubahan perilaku atau pembentukan perilaku (Hidayatullah, 2017).

Mewujudkan pengetahuan maka individu di stimulus dengan pendidikan kesehatan. Setelah seseorang mengetahui stimulus proses selanjutnya iya akan menilai/bersikap terhadap stimulus tersebut. Oleh sebab itu indikator untuk sikap kesehatan juga sejalan dengan pengetahuan kesehatan (Meidina, 2017). Reaksi atau respon yang masih tertutup dari seseorag merupakan sikap seseorang terhadap suatu stimulus atau objek. Sikap belum merupakan suatu tindakan atau aktivitas, akan tetapi merupakan predisposisi tindakan suatu prilaku (Meidina, 2017).

Hasil penelitian ini menunjukkan bahwa responden yang diberikan media video menunjukkan perilaku yang tinggi langsung dalam melakukan tindakan dalam pencegahan malaria hal ini didukung oleh pengetahuan responden yang baik dalam tindakan pencegahan malaria, karena seseorang akan mengadopsi perilaku dengan sebelumnya ia harus tahu manfaat bagi dirinya (Meidina, 2017).

Hasil penelitian ini sejalan dengan hasil penelitian yang pernah dilakukan mengenai penggunaan media audio visual dapat berpengaruh terhadap sikap ibu dalam penanganan ISPA pada balita di Kelurahan Lebijaga Kabupaten Ngada (Hidayatullah, 2017) dimana media audio visual ini dapat digunakan oleh perawat sebagai media penyuluhan yang baik. 
Berdasarkan pembahasan di atas dapat disimpulkan bahwa pemberian edukasi dengan menggunakan media berpengaruh meningkatkan sikap responden. Media audio-visual mendorong keinginan untuk mengetahui lebih banyak (Doro, 2016). Media audio-visual tidak saja menghasilkan cara belajar yang efektif dalam waktu yang lebih singkat, akan tetapi apa yang diterima melalui media audio-visual lebih lama dan lebih baik tinggal dalam ingatan. Perubahan perilaku reponden dapat dipengaruhi oleh informasi yang diperoleh baik secara informal maupun secara formal. Pemberian informasi secara formal maupun nonformal dapat meningkatkan pengetahuan (Ilmiah, 2017).

Pemberian informasi formal dapat diperoleh oleh responden dari tenaga kesehatan saat berkunjung ke fasilitas kesehatan maupun melalui non formal seperti melalui media massa, televisi, radio, membaca informasi mengenai pencegahan malaria atau memperoleh informasi dari keluarga atau orang lain. Selain itu responden atau keluarga yang pernah mengalami sakit malaria akan berusaha untuk melakukan pencegahan terhadap malaria agar tidak kembali mengalami sakit malaria. Pengalaman sakit malaria dan pemberian informasi secara formal dan non formal inilah yang dapat mengubah perilaku responden untuk melakukan pencegahan malaria.

\section{KESIMPULAN}

Kesimpulan dalam penelitian ini yaitu, tidak adanya peningkatan pengetahuan responden tentang penanganan malaria sebelum dan sesudah diberikan video sebagai media edukasi dalam penanganan malaria dengan hasil uji statistik wilcoxon pada pretest dan postest pengetahuan didapatkan p-value $=0,434$. Adanya perubahan perilaku responden tentang penanganan malaria sebelum dan sesudah diberikan video sebagai media edukasi dalam penanganan malaria dengan hasil uji statistik wilcoxon pada pretest dan postest pengetahuan didapatkan pvalue $=0,004$. Media video dapat dijadikan sebagai media edukasi dalam pendidikan kesehatan yang efektif digunakan dalam memperbaiki dan meningkatkan tindakan responden terhadap penanganan penyakit malaria.

\section{UCAPAN TERIMA KASIH}

Terima kasih kepada Bapak Kepala Puskesmas Maripi yang telah memberikan izin untuk melakukan penelitian.

\section{SUMBER RUJUKAN}

1. Kemenkes RI. (2016). Pusat Data Dan Informasi Penyakit Malaria (pp. 1-7). pp. 1-7. https://doi.org/10.1007/s10583006-9000-X

2. Darmiah, B., Khair, A., \& Isnawati, Y. S. (2017). Hubungan tingkat pengetahuan dan pola perilaku dengan kejadian malaria di Kabupaten Katingan Provinsi Kalimantan Tengah. JHECDs, 3(2), 36-41.

3. Occurrence, C. (2018). Unnes Journal 
of Public Health. 7(2), 110-119.

4. suci,arief widodo, endang. (2013). Hubungan Tingkat Pengetahuan Ibu Tentang Upaya Pencegahan Malaria Dengan Kejadian Malaria Pada Anak Usia 0-9 Tahun Di Puskesmas Timika Jaya Mimika Papua. 84, 487-492.

5. Hakim,1. (2011). Malaria : Epidemiology And Diagnostic. Aspirator, 3(2), 107-116.

6. Bandura, a, Barbaranelli, c., Caprara, g. V, \& Pastorelli, c. (2008). Child development, 72(1), 187-206. Universitas sumatera utara. https://doi.org/10.1007/s13398-0140173-7.2

7. Budiman dan riyanto (2013): (2016). Faktor Yang Mempengaruhi Pengetahuan. 9-29. Https://doi.org/10.1007/s13398-0140173-7.2

8. Ii, b. A. B. (2009). Hubungan Antara Perilak. Pipit Puspitasari, Fakultas Ilmu Kesehatan UMP, 2016. (2007).

9. Zakiyatun, c., \& ashari, r. (2017). Pengaruh Media Peta Konsep Dalam Model Pembelajaran Kooperatif Tipe Numbered Heads Together ( Nht ) Terhadap Hasil Belajar Dan Daya
Ingat Siswa. 5(2). Ar-razi jurnal ilmiah

10. Hidayatullah, p., dan, p., kota, u., \& tahun, k. (2017). No title. 2(6), 1-11.

11. Meidiana, r., Simbolon, d., \& Wahyudi, A. (2018). Pengaruh Edukasi melalui Media Audio Visual terhadap Pengetahuan dan Sikap Remaja Overweight. 9(November), 478-484.

12. Ilmiah, J., Batanghari, U., \& Vol, J. (2017). Pengaruh Pendidikan Kesehatan Dengan Media Leaflet Terhadap Pengetahuan Ibu Tentang Penatalaksanaan Ispa Pada Balita Di Posyandu Tina Yuli Fatmawati 1. 17(3), 227-234. 
